\title{
Anti-Müllerian hormone inhibits proliferation and induces apoptosis in epithelial ovarian cancer cells by regulating the cell cycle and decreasing the secretion of stem cell factor
}

\author{
TIANSONG ZHANG ${ }^{1 *}$, LINHAO DENG ${ }^{2 *}$, QIAN XIONG ${ }^{3}$, SHUJUN $\mathrm{SU}^{3}$ and JIAN GU ${ }^{3}$ \\ ${ }^{1}$ Department of Obstetrics and Gynecology, Guangzhou Women and Children's Medical Center, Guangzhou, \\ Guangdong 510623; ${ }^{2}$ Department of Obstetrics and Gynecology, Jieyang People's Hospital, Jieyang, \\ Guangdong 522000; ${ }^{3}$ Department of Gynecology, The Third Affiliated Hospital of Sun Yat-Sen University, \\ Guangzhou, Guangdong 510630, P.R. China
}

Received October 2, 2017; Accepted May 18, 2018

DOI: $10.3892 / \mathrm{ol} .2018 .8985$

\begin{abstract}
Anti-Müllerian hormone (AMH) has been demonstrated to exhibit an inhibitory effect on the proliferation, invasion, metastasis and drug resistance of ovarian cancer. However, the mechanisms underlying these effects remain unclear. In the present study, $10 \mu \mathrm{g} / \mathrm{ml}$ recombinant human AMH (rhAMH) was administered to human OVCAR3 and OVCAR8 epithelial ovarian cancer (EOC) cell lines. Cell proliferation, apoptosis and cell cycle were analyzed. The level of stem cell factor (SCF) was detected using a reverse transcription-quantitative polymerase chain reaction and an ELISA, respectively. The exogenous addition of rhAMH significantly reduced the proliferation of OVCAR3 and OVCAR8 cell lines compared with the control group $(\mathrm{P}<0.01)$. The apoptosis rate in the rhAMH treated group (48 h) significantly increased compared with in the control group (OVCAR3, $\mathrm{P}=0.035$; OVCAR8, $\mathrm{P}=0.020$ ). The apoptosis rate increased at $72 \mathrm{~h}$ but did not exhibit a significant difference when compared with the $48 \mathrm{~h}$ group (OVCAR3, $\mathrm{P}=0.145$; OVCAR8, $P=0.296$ ). The percentage of cells in the $G_{1}$ phase in the rhAMH treated group $(48 \mathrm{~h})$ increased but was not significantly different compared with the control group (OVCAR3, $\mathrm{P}=0.070$; OVCAR8, $\mathrm{P}=0.051)$. However, there was a significant
\end{abstract}

Correspondence to: Dr Jian Gu, Department of Gynecology, The Third Affiliated Hospital of Sun Yat-Sen University, 600 Tianhe Road, Guangzhou, Guangdong 510630, P.R. China

E-mail: doctorgujian@163.com

*Contributed equally

Abbreviations: AMH, anti-Müllerian hormone; AMHRII, anti-Müllerian hormone type II receptor; EOC, epithelial ovarian cancer; rhAMH, recombinant human anti-Müllerian hormone; SCF, stem cell factor

Key words: anti-Müllerian hormone, epithelial ovarian cancer, cell cycle, stem cell factor difference at $72 \mathrm{~h}$ compared with the control group (OVCAR3, $\mathrm{P}=0.016$; OVCAR8, $\mathrm{P}=0.019)$. At $48 \mathrm{~h}$, the rhAMH-treated group exhibited a statistically significant inhibition of SCF mRNA expression levels $(\mathrm{P}=0.008)$, but no significant difference in the protein expression levels $(\mathrm{P}=0.101)$ compared with the control, though a significant inhibition was exhibited at $72 \mathrm{~h}$ (mRNA expression levels, $\mathrm{P}=0.005$; protein expression levels, $\mathrm{P}=0.036$ ). The present study revealed that rhAMH may be able to inhibit the proliferation and induce the apoptosis of EOC cells via $G_{1} / S$-phase cell cycle arrest and the decreased secretion of SCF.

\section{Introduction}

Epithelial ovarian cancer (EOC) is the most common histological type of ovarian cancer, and is the gynecological malignancy with the highest mortality rate. It was estimated that globally, 21,980 new cases and 14,270 mortalities occurred in 2014 as a consequence of EOC (1). The main reasons for the high mortality rate include a lack of diagnostic methods appropriate for early stage detection and a lack of effective treatment strategies (2). Therefore, understanding the molecular pathogenesis and uncovering the associated molecular biomarkers of EOC may facilitate earlier detection and improve the survival of patients with ovarian cancer.

In addition to serving a crucial function in the regression of the Müllerian duct and the regulation of folliculogenesis $(3,4)$, the anti-Müllerian hormone (AMH) has been previously studied for the potential expansion of its application against ovarian cancer. Accumulating evidence has demonstrated that AMH exhibits an inhibitory effect on the proliferation, invasion, metastasis and drug resistance of ovarian cancer in vitro and in vivo, through binding to its specific receptor, named AMH type II receptor (AMHRII) $(5,6)$. In particular, ovarian cancer stem cells, which facilitate resistance to chemotherapeutic agents in addition to serving an integral function in tumor recurrence, are inhibited by AMH (7-9). In order to examine its toxicity, AMH was tested in vivo using female nude mice for a total of 20 weeks, and significant inhibition of tumor growth was observed without 
notable toxicity (10). Therefore, AMH may be a promising anticancer drug for this gynecological malignancy.

An increasing number of studies have confirmed that stem cell factor (SCF) serves a key function in tumor occurrence, development, migration and recurrence, through activating downstream signaling molecules, following interaction with its receptor, c-kit (11-14). SCF interacting with c-kit via autocrine or paracrine signaling has been identified in the majority of ovarian cancer types, and results in the enhanced proliferation, invasion, anti-apoptosis and drug resistance of cancer cells (12-14). In addition, with respect to the development of follicles, AMH was demonstrated to be a modulatory factor that decreases the expression of SCF via the cyclic adenosine monophosphate (cAMP)/protein kinase A (PKA) pathway (15).

The underlying mechanism of AMH-mediated growth inhibition in EOC remains unclear. The present study was performed to investigate if $\mathrm{AMH}$ inhibits proliferation and induces apoptosis in EOC cells via regulating the cell cycle and the downregulation of SCF.

\section{Materials and methods}

Cell culture. Human EOC cell lines (OVCAR3 and OVCAR8) purchased from the Institute of Biochemistry and Cell Biology at the Chinese Academy of Sciences (Shanghai, China) were cultured in Dulbecco's modified Eagle's medium (DMEM; Gibco; Thermo Fisher Scientific, Inc., Waltham, MA, USA) supplemented with $10 \%$ fetal bovine serum (Invitrogen; Thermo Fisher Scientific, Inc.). No antibiotics were used. The cells were incubated in a humidified atmosphere containing $5 \% \mathrm{CO}_{2}$ at $37^{\circ} \mathrm{C}$. Recombinant human AMH (rhAMH; R\&D Systems, Inc., Minneapolis, MN, USA) was diluted with $10 \%$ fetal bovine serum to $10 \mu \mathrm{g} / \mathrm{ml}$ for subsequent experiments.

Cell proliferation assay. An MTT assay was used to detect cell proliferation. Briefly, EOC OVCAR3 and OVCAR8 cell lines (1,500 cells/well) were seeded into 96 -well plates, incubated in a humidified atmosphere containing $5 \% \mathrm{CO}_{2}$ at $37^{\circ} \mathrm{C}$ overnight to allow for cell attachment and recovery, and then exposed to $10 \mu \mathrm{g} / \mathrm{ml} \mathrm{rhAMH}$, or fetal bovine serum without rhAMH. The cells were cultured for the indicated intervals (48 and $72 \mathrm{~h}$ ) and then stained with sterile MTT dye $(0.5 \mathrm{mg} / \mathrm{ml}$; Sigma-Aldrich; Merck KGaA, Darmstadt, Germany). After $4 \mathrm{~h}$ of incubation at $37^{\circ} \mathrm{C}$, the supernatant was aspirated, and dimethyl sulfoxide (Sigma-Aldrich; Merck KGaA) was added to dissolve the purple formazan. The absorbance was measured at $490 \mathrm{~nm}$. All experiments were performed in triplicate.

Cell apoptosis detection. Two EOC OVCAR3 and OVCAR8 cell lines in each group were seeded into 6-well plates at a density of $1 \times 10^{6} / \mathrm{ml}$. After 48 and $72 \mathrm{~h}$ of exposure to rhAMH at $37^{\circ} \mathrm{C}$, cells were harvested and washed twice with pre-chilled PBS followed by centrifugation $(100 \mathrm{x} \mathrm{g})$ at $4^{\circ} \mathrm{C}$ for $5 \mathrm{~min}$. Approximately $5 \times 10^{5}$ cells were collected. For apoptosis analysis, a Dead Cell Apoptosis kit with Annexin V/fluorescein isothiocyanate (FITC) and propidium iodide (PI) for flow cytometry (BD Biosciences, Franklin Lakes, NJ, USA) was used according to the manufacturer's protocol. Briefly, following washing twice with PBS, cells were re-suspended in $1 \mathrm{x}$ Annexing binding buffer at a density of $1 \times 10^{6}$ cells $/ \mathrm{ml}$. Then, $5 \mu \mathrm{l}$ Annexin V/FITC and $1 \mu \mathrm{l} 100 \mu \mathrm{g} / \mathrm{ml}$ PI were added to each $100 \mu 1$ cell suspension, and the samples were incubated at room temperature for $15 \mathrm{~min}$ in the dark. Following incubation, apoptosis was analyzed using fluorescence-activated cell sorting (FACS; BD Biosciences, Franklin Lakes, NJ, USA) using Cell-Quest software version 5.1 (BD Biosciences) within $1 \mathrm{~h}$. The cells undergoing apoptosis were those that were Annexin V FITC-positive and PI-negative. All experiments were repeated three times.

Cell cycle analysis. Two EOC OVCAR3 and OVCAR8 cell lines in each group were seeded in six-well plates with $1 \times 10^{6} / \mathrm{ml}$. After 48 or $72 \mathrm{~h}$ exposure to rhAMH at $37^{\circ} \mathrm{C}$, cells were harvested and washed twice with pre-chilled PBS, then fixed in pre-chilled $70 \%$ ethanol at $4^{\circ} \mathrm{C}$ overnight. The fixed cells were washed with $1 \mathrm{ml} \mathrm{PBS,} 100 \mu \mathrm{g} / \mathrm{ml}$ RNase A was then added, and then incubated at $37^{\circ} \mathrm{C}$ for $30 \mathrm{~min}$. Approximately 20,000-30,000 cells were counted using a flow cytometer (BD Biosciences), detecting red fluorescence at an excitation wavelength of $488 \mathrm{~nm}$.

$R N A$ isolation and reverse transcription-quantitative polymerase chain reaction ( $R T-q P C R)$ analysis. Total RNA from two EOC OVCAR3 and OVCAR8 cell lines was extracted using TRIzol reagent (Invitrogen; Thermo Fisher Scientific, Inc.). RT-qPCR was performed using the Moloney Murine Leukemia Virus reverse transcriptase (Promega Corporation, Madison, WI, USA) and platinum SYBR Green qPCR SuperMix-UDG reagents (Invitrogen; Thermo Fisher Scientific, Inc.). Primers were designed for human AMHRII (forward, 5'-TCCCAAGGC CAATATAAACC-3' and reverse, 5'-TTATCCAGAGAACTC ACTTCCA-3'), human SCF (forward, 5'-TCCACCATGGGA GAGCCTAA-3' and reverse, 5'-AGTAACCTAGTTTTCAAC ACCCA-3') and $\beta$-actin (forward, 5'-CTCTGGCCGTACCAC TGGC-3' and reverse, 5'-GTGAAGCTGTAGCCGCGC-3'). $\beta$-actin was used as the internal control. qPCR was performed with an initial denaturation step at $95^{\circ} \mathrm{C}$ for $30 \mathrm{sec}$, followed by 40 cycles of $95^{\circ} \mathrm{C}$ for $5 \mathrm{sec}$ and $60^{\circ} \mathrm{C}$ for $40 \mathrm{sec}$. The PCR products were run on a $1 \%$ agarose Tris-acetate-EDTA gel. The relative fold changes in mRNA expression were calculated using the $2^{-\Delta \Delta \mathrm{Cq}}$ method (16).

ELISA. The protein levels of SCF were detected in OVCAR8 cell line culture supernatants and tumor homogenate using a Human SCF ELISA kit (DCK00; R\&D Systems, Inc.) according to the manufacturer's protocol. All samples were assayed in triplicate.

Statistical analysis. Measurement data were expressed as the mean \pm standard deviation. Comparisons between two independent samples were performed using a Student's t-test. Additionally, one-way analysis of variance followed by Fisher's least significant difference test was applied for comparisons among multiple groups. SPSS v.16.0 statistical software (SPSS, Inc., Chicago, IL, USA) was used for statistical analysis. $\mathrm{P}<0.05$ was considered to indicate a statistically significant difference. 


\section{Results}

AMHRII detected by RT-qPCR in EOC cell lines. OVCAR3 and OVCAR8 cell lines were revealed to express AMHRII mRNA. Electrophoretic gel examination of the PCR products confirmed an appropriate band of the predicted length of 200 bp for AMHRII in the two cell lines (Fig. 1).

RhAMH inhibits EOC cell proliferation. To identify the role of rhAMH in the proliferation of EOC cells, an MTT assay was conducted using OVCAR3 and OVCAR8 cell lines. Compared with the control group (treated with fetal bovine serum without rhAMH), the exogenous addition of rhAMH $(10 \mu \mathrm{g} / \mathrm{ml})$ at $37^{\circ} \mathrm{C}$ significantly reduced the proliferation of the two cell lines $(\mathrm{P}<0.01$; Fig. 2). At $72 \mathrm{~h}$ after exposure, the inhibition was greater compared with at $48 \mathrm{~h}$.

RhAMH induces EOC cell apoptosis. Cell apoptosis was analyzed using FACS. Annexin V-FITC staining was used to detect early-stage apoptosis in cells treated with rhAMH. The results revealed that the apoptosis rate in the rhAMH treated group (48 h) was significantly increased compared with the control group (OVCAR3, $\mathrm{P}=0.035$; OVCAR8, $\mathrm{P}=0.020$ ). The apoptosis rate increased at $72 \mathrm{~h}$, but was not statistically significantly different when compared with the 48 h group (OVCAR3, P=0.145; OVCAR8, P=0.296; Fig. 3A and B).

RhAMH induces $G_{I} / S$ cell cycle arrest in EOC cells. Exogenous addition of $\mathrm{rhAMH}(10 \mu \mathrm{g} / \mathrm{ml})$ substantially increased the percentage of cells at the $\mathrm{G}_{1}$ phase and decreased the percentage of cells in the $S$ phase. The percentage of cells in the $G_{1}$ phase in the rhAMH treated group (48 h) increased but was not significantly different when compared with the control group (OVCAR3, P=0.070; OVCAR8, $\mathrm{P}=0.051$ ). However, there was a significant difference at $72 \mathrm{~h}$ compared with the control group (OVCAR3, P=0.016; OVCAR8, P=0.019; Fig. 3C). The result of the single test via flow cytometry is shown in Fig. 3D. These results suggested that rhAMH may induce $\mathrm{G}_{1} / \mathrm{S}$-phase arrest in EOC cells.

RhAMH enhanced the transcriptional activity and protein expression of SCF. The interaction between SCF and c-kit enhances cell proliferation and suppresses apoptosis (11-14). To further investigate the molecular mechanisms underlying the rhAMH-mediated effects on proliferation, apoptosis and the cell cycle, the levels of SCF in culture supernatants and tumor homogenates were detected using RT-qPCR and ELISA. As presented in Fig. 4A and B, SCF was downregulated following treatment with rhAMH in OVCAR8 cells. Treatment with rhAMH for $48 \mathrm{~h}$ resulted in the significant inhibition of SCF mRNA expression levels $(\mathrm{P}=0.008)$ but did not significantly affect the protein expression level $(\mathrm{P}=0.101)$ compared with the control, while the mRNA and protein expression levels were significantly inhibited at $72 \mathrm{~h}$ (mRNA expression levels, $\mathrm{P}=0.005$; protein expression levels, $\mathrm{P}=0.036$ ).

\section{Discussion}

Although the biological characteristics of ovarian malignant tumor types have been widely investigated in previous

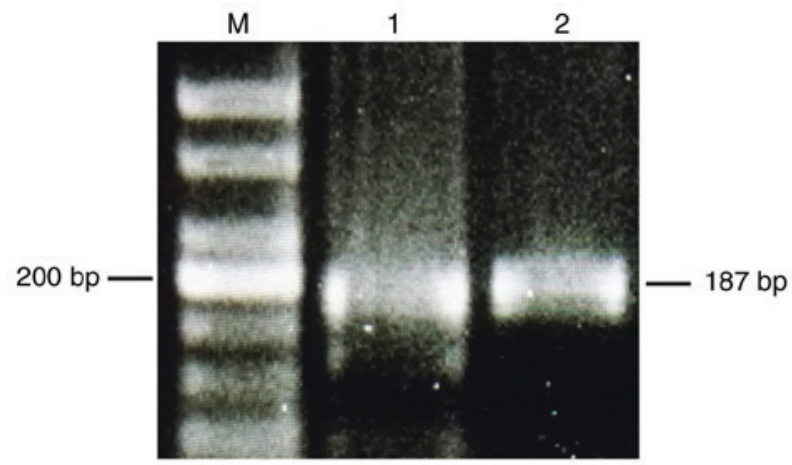

Figure 1. Anti-Müllerian hormone type II receptor was detected by reverse transcription-polymerase chain reaction in epithelial ovarian carcinoma cell lines. Bp, base pair; M, marker; 1, OVCAR3; 2, OVCAR8.

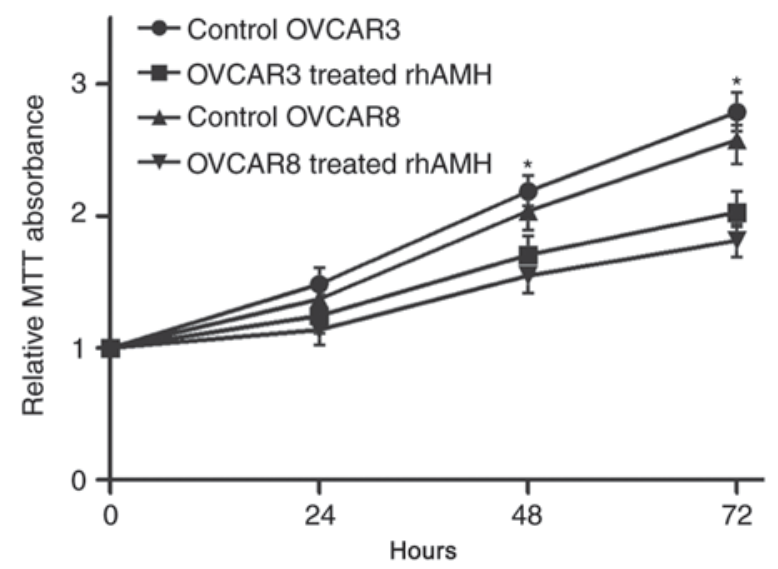

Figure 2. MTT assays to assess the proliferation of OVCAR3 and OVCAR8 cells following treatment with rhAMH. ${ }^{*} \mathrm{P}<0.01$ vs. the control. RhAMH, recombinant human anti-Müllerian hormone.

decades, the prognosis remains poor, with the 5-year survival rate of advanced ovarian cancer being $<30 \%$ (2). Therefore, there is an urgent requirement to develop effective drugs that reduce the risk of recurrence subsequent to first-line treatment and inhibit drug-resistant cancer. Previous studies have revealed that the physiological hormone AMH may not only specifically suppress the proliferation, invasion and metastasis of AMHRII-positive ovarian cancer, but that it may additionally reduce drug resistance $(17,18)$, suggesting that AMH may have potential therapeutic uses against ovarian cancer. In the present study, a commonly used low dose $(10 \mu \mathrm{g} / \mathrm{ml})$ of rhAMH was administered to OVCAR3 and OVCAR8 cells in vitro. The results revealed that, compared with the control group, rhAMH inhibited EOC cell proliferation, induced apoptosis and resulted in a time-dependent $\mathrm{G}_{1} / \mathrm{S}$-phase cell cycle arrest. These results suggest that the suppression of proliferation and the induction of apoptosis by $\mathrm{AMH}$ may occur via blocking the transition from the $\mathrm{G}_{1}$ to the $\mathrm{S}$ phase.

One previous study has revealed that exogenous $\mathrm{AMH}$ may activate the Smad family member 1/5 signaling pathway in ovarian granulosa cell tumor types, leading to the activation of caspase-3 and consequently to apoptosis (19). $\mathrm{G}_{1} / \mathrm{S}$-phase cell cycle arrest may be exerted via upregulating the cyclin-dependent kinase inhibitor p16 through 

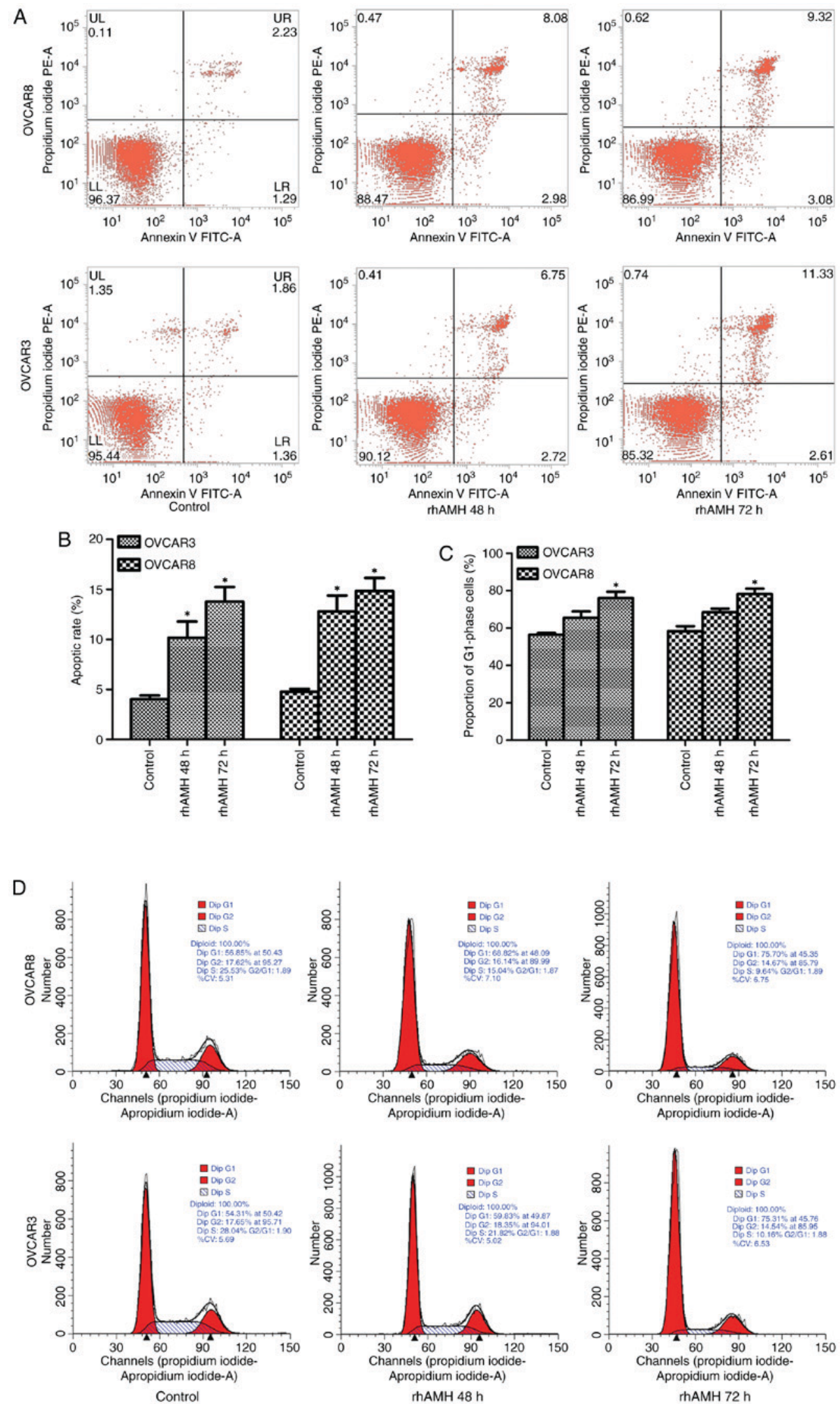

Figure 3. OVCAR3 and OVCAR8 cell apoptosis detection by fluorescence-activated cell sorting and cell cycle analysis by flow cytometry. (A) Cell apoptosis was analyzed using Annexin V FITC and (B) quantified. The apoptosis rate in the rhAMH treated group $(48 \mathrm{~h})$ was significantly increased compared with the control group (OVCAR3, $\mathrm{P}=0.035$; OVCAR8, $\mathrm{P}=0.020$ ). The apoptosis rate increased at $72 \mathrm{~h}$ but was not significantly different compared with the $48 \mathrm{~h}$ group (OVCAR3, $\mathrm{P}=0.145$; OVCAR8, $\mathrm{P}=0.296$ ). (C) Quantified flow cytometry revealed the number of cells at the $\mathrm{G}_{1}$ phase. The percentage of cells at $\mathrm{G}_{1}$ phase in the rhAMH treated group $(48 \mathrm{~h})$ increased, but was not significantly different when compared with the control group $(\mathrm{OVCAR} 3, \mathrm{P}=0.070$; OVCAR8, P=0.051). A significant difference was identified at $72 \mathrm{~h}$ compared with the control group (OVCAR3, $\mathrm{P}=0.016$; OVCAR8, $\mathrm{P}=0.019$ ). (D) Flow cytometry results. ${ }^{*} \mathrm{P}<0.01$ vs. the control. RhAMH, recombinant human anti-Müllerian hormone; FITC, fluorescein isothiocyanate. 

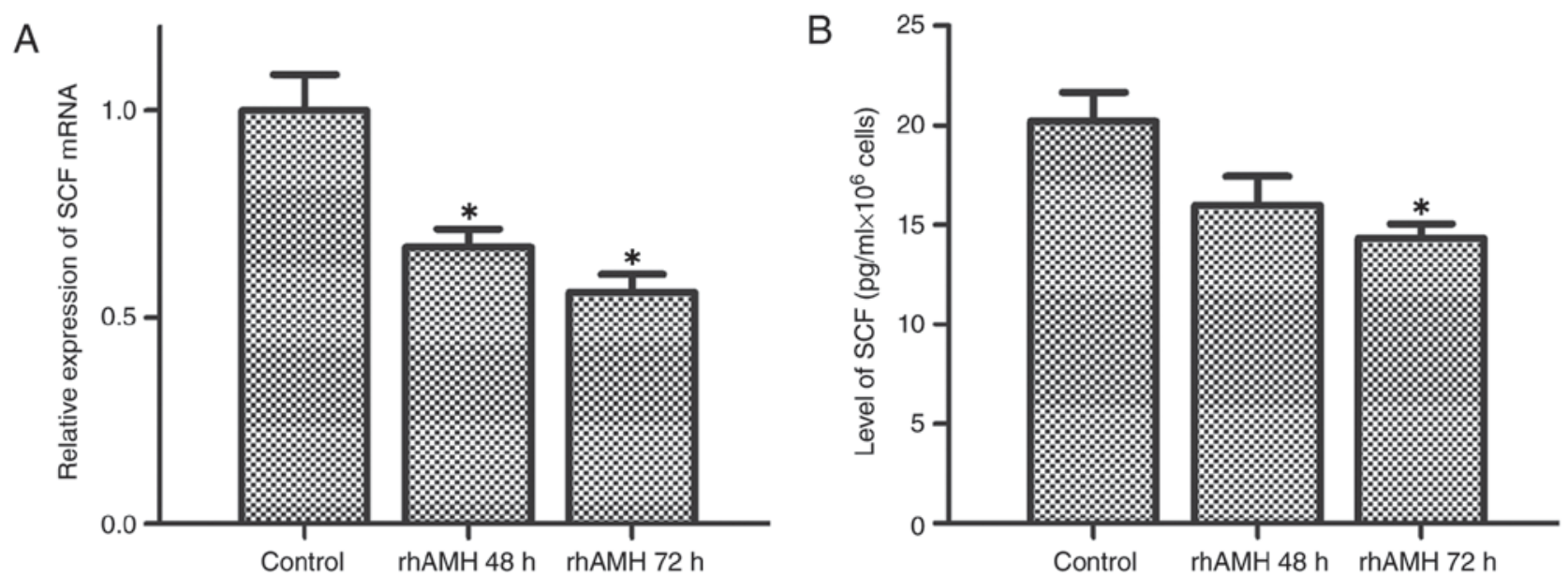

Figure 4. Transcriptional activity of SCF detected by a reverse transcription-quantitative polymerase chain reaction, and protein expression levels detected by enzyme-linked immunosorbent assay in the OVCAR8 cell line. (A) mRNA expression levels of SCF, which were significantly inhibited at 48 (P=0.008) and $72 \mathrm{~h}(\mathrm{P}=0.005)$. (B) Protein expression levels of $\mathrm{SCF}$, which were not significantly inhibited at $48 \mathrm{~h}(\mathrm{P}=0.101)$ but were significantly inhibited at $72 \mathrm{~h}$ compared with the control group $(\mathrm{P}=0.036) .{ }^{*} \mathrm{P}<0.01$ vs. the control. SCF, stem cell factor.

an AMHRII-mediated mechanism and inhibiting growth in the absence of detectable or inactive retinoblastoma $(\mathrm{Rb})$ protein (20). Prolonged treatment with rhAMH downregulates the $\mathrm{Rb}$-associated protein $\mathrm{p} 130$ and increases the $\mathrm{Rb}$ family-regulated transcription factor E2F transcription factor 1 , the overexpression of which inhibits the growth of EOC (20).

In the present study, the biological agent (rhAMH) mediating the afore-described functions was investigated. SCF serves an important function in the recurrence, development, invasion, metastasis and drug resistance of a variety of malignant tumor types (12-14). Previous studies have also revealed that rhAMH may inhibit the expression of SCF in normal ovarian epithelial cells and granular cells $(15,21)$. Preliminary experiments in the present study detected the expression of SCF in the OVCAR8 cell line. Subsequently, the mRNA and protein expression levels of SCF in the OVCAR8 cell line at 48 and $72 \mathrm{~h}$ following rhAMH treatment were examined. The results demonstrated that rhAMH reduced SCF mRNA transcription and protein levels in OVCAR8 cells, suggesting that SCF may be involved in the process of AMH-mediated inhibition of ovarian cancer. The inhibition was increased further at $72 \mathrm{~h}$, suggesting that rhAMH may exert a time-dependent suppression of SCF secretion.

One previous study by Zhang et al (22) demonstrated that SCF may increase mast cell numbers and microvascular density in a tumor. The expression of von Willebrand factor, an endothelial cell marker, was also increased, suggesting that SCF modulates tumor growth and angiogenesis via the involvement of mast cells (22). A study by Huang et al (23) further revealed that SCF may not only effectively recruit mast cells, which express multiple proinflammatory factors and increase interleukin-17 expression in a tumor, but that it may also exacerbate tumor immunosuppression by releasing adenosine and increasing T-regulatory cells, which augment the suppression of $\mathrm{T}$ cells and natural killer cells in a tumor. Additionally, bone marrow-derived suppression cells may in turn stimulate tumor cells to secrete a soluble form of SCF, further activating mast cells through the secretion of matrix metalloproteinase 9 (24). A study by Shaw and Vanderhyden (25) revealed that exogenous SCF may induce drug-resistance and apoptosis resistance in ovarian cancer cells, while the c-kit neutralizing antibody anti-c-kit antibody and c-kit inhibitor imatinib mesylate may bind precisely to c-kit, enhancing the chemosensitivity and inducing the apoptosis of ovarian cancer cells. Taken together with the results of the present study, it may be proposed that the joint administration of rhAMH and imatinib reduce the side effects and improve the antitumor effects for patients with ovarian cancer. Another study also revealed that treatment of EOC cells with rhAMH combined with calcitriol resulted in the inhibition of cell growth and survival (26). The combined treatment significantly suppressed cell growth, downregulated the expression of B-cell lymphoma 2 , and upregulated the expression of Bcl-2-associated X protein, caspase- 3 and caspase- 9 through the extracellular signal-regulated kinase signaling pathway (26). Researchers have further investigated the underlying pathways involving the function of SCF in the inhibition of AMHRII-positive ovarian cancer cells. Hu et al (15) revealed that rhAMH may reduce the mRNA transcription and protein expression levels of SCF through the cAMP/PKA pathway in human granulosa cells. A study by Katiyar et al (27) identified that the proto-oncogene c-Jun may induce SCF protein, mRNA and promoter activity. Induction of the SCF promoter required the c-Jun DNA-binding domain (27).

A number of limitations of the present study should be addressed. Firstly, EOC cells may have a mutation of AMHRII, which affect the level and function of AMHRII. The study was divided into the control group and rhAMH-treated $(\mathrm{AMHR}+)$ group. However, there was no rhAMH-treated (AMHR-) cells designed. Secondly, OVCAR3 and OVCAR8 were cultured for considerable periods of time and may be unreliable. However, the present study primarily focused on the AMHRII expression of EOC cells according to previous studies $(26,28)$. No inconsistent or variable responses of these cell lines were observed. In future studies the study design will be improved by using a greater number of EOC 
cell lines. Thirdly, the rhAMH was purchased from R\&D Systems, Inc., which has been previously demonstrated to be inactive in a Müllerian duct regression assay (29). The same product, purchased from alternative companies, will be used in future studies. Finally, the working concentration of rhAMH was diluted to $10 \mu \mathrm{g} / \mathrm{ml}$ according to previous experiments $(30,31)$. It would have been ideal to instead perform a dose-response analysis to identify the optimal working concentration.

To conclude, the present study revealed that rhAMH may be able to inhibit the proliferation and induce the apoptosis of EOC cells via $G_{1} / S$-phase cell cycle arrest and decreased SCF secretion. In addition, it was demonstrated that rhAMH may inhibit the synthesis of SCF in EOC cells at the transcription and translation levels. Future studies will evaluate the effects of a higher concentration of rhAMH, applied to a greater number of ovarian cancer cell lines. Silencing or upregulating SCF via cell transfection may illuminate the direct function of SCF in ovarian cancer, and the various pathways involved. In addition, the number of immunocytes in tumor tissue, the microvascular density and the levels of associated inflammatory factors in EOC will be evaluated.

\section{Acknowledgements}

Not applicable.

\section{Funding}

The present study was supported by the Female Cancer Drug Program of Guangdong Province Pharmaceutical Society (grant no. 2014D08) awarded to Dr Jian Gu (Department of Gynecology, The Third Affiliated Hospital of Sun Yat-Sen University, Guangdong, China).

\section{Availability of data and materials}

The datasets used and/or analyzed during the current study are available from the corresponding author on reasonable request.

\section{Authors' contributions}

TZ and JG conceived and designed the study. QX performed the flow cytometry assay. TZ and LD performed all other experiments. SS carried out statistical analysis and interpreted results. All drafts of the reports were written by TZ and LD. All authors read and approved the final paper.

\section{Ethics approval and consent to participate}

Not applicable.

\section{Patient consent for publication}

Not applicable.

\section{Competing interests}

The authors declare that they have no competing interests.

\section{References}

1. Siegel RL, Miller KD and Jemal A: Cancer statistics, 2017. CA Cancer J Clin 67: 7-30, 2017.

2. Lowe KA, Chia VM, Taylor A, O'Malley C, Kelsh M, Mohamed M, Mowat FS and Goff B: An international assessment of ovarian cancer incidence and mortality. Gynecol Oncol 130: 107-114, 2013.

3. Durlinger AL, Gruijters MJ, Kramer P, Karels B, Kumar TR, Matzuk MM, Rose UM, de Jong FH, Uilenbroek JT, Grootegoed JA and Themmen AP: Anti-Müllerian hormone attenuates the effects of FSH on follicle development in the mouse ovary. Endocrinology 142: 4891-4899, 2001.

4. Durlinger AL, Kramer P, Karels B, de Jong FH, Uilenbroek JT, Grootegoed JA and Themmen AP: Control of primordial follicle recruitment by anti-Müllerian hormone in the mouse ovary. Endocrinology 140: 5789-5796, 1999.

5. Masiakos PT, MacLaughlin DT, Maheswaran S, Teixeira J, Fuller AF Jr, Shah PC, Kehas DJ, Kenneally MK, Dombkowski DM, Ha TU, et al: Human ovarian cancer, cell lines, and primary ascites cells express the human Müllerian inhibiting substance (MIS) type II receptor, bind, and are responsive to MIS. Clin Cancer Res 5: 3488-3499, 1999.

6. Stephen AE, Pearsall LA, Christian BP, Donahoe PK, Vacanti JP and MacLaughlin DT: Highly purified Müllerian inhibiting substance inhibits human ovarian cancer in vivo. Clin Cancer Res 8: 2640-2646, 2002.

7. Meirelles K, Benedict LA, Dombkowski D, Pepin D, Preffer FI, Teixeira J, Tanwar PS, Young RH, MacLaughlin DT, Donahoe PK and Wei X: Human ovarian cancer stem/progenitor cells are stimulated by doxorubicin but inhibited by Müllerian inhibiting substance. Proc Natl Acad Sci USA 109: 2358-2363, 2012.

8. Wei X, Dombkowski D, Meirelles K, Pieretti-Vanmarcke R, Szotek PP, Chang HL, Preffer FI, Mueller PR, Teixeira J, MacLaughlin DT and Donahoe PK: Müllerian inhibiting substance preferentially inhibits stem/progenitors in human ovarian cancer cell lines compared with chemotherapeutics. Proc Natl Acad Sci USA 107: 18874-18879, 2010.

9. Szotek PP, Pieretti-Vanmarcke R, Masiakos PT, Dinulescu DM, Connolly D, Foster R, Dombkowski D, Preffer F, Maclaughlin DT and Donahoe PK: Ovarian cancer side population defines cells with stem cell-like characteristics and Müllerian Inhibiting Substance responsiveness. Proc Natl Acad Sci USA 103: 11154-11159, 2006.

10. Pieretti-Vanmarcke R, Donahoe PK, Szotek P, Manganaro T, Lorenzen MK, Lorenzen J, Connolly DC, Halpern EF and MacLaughlin DT: Recombinant human Müllerian inhibiting substance inhibits long-term growth of MIS type II receptor-directed transgenic mouse ovarian cancers in vivo. Clin Cancer Res 12: 1593-1598, 2006.

11. Liang J, Wu YL, Chen BJ, Zhang W, Tanaka Y and Sugiyama H: The C-kit receptor-mediated signal transduction and tumor-related diseases. Int J Biol Sci 9: 435-443, 2013.

12. Tonary AM, Macdonald EA, Faught W, Senterman MK and Vanderhyden BC: Lack of expression of c-KIT in ovarian cancers is associated with poor prognosis. Int $\mathrm{J}$ Cancer 89: 242-250, 2000.

13. Wilczynski SP, Chen YY, Chen W, Howell SB, Shively JE and Alberts DS: Expression and mutational analysis of tyrosine kinase receptors c-kit, PDGFRalpha, and PDGFRbeta in ovarian cancers. Hum Pathol 36: 242-249, 2005.

14. Arber DA, Tamayo R and Weiss LM: Paraffin section detection of the c-kit gene product (CD117) in human tissues: Value in the diagnosis of mast cell disorders. Hum Pathol 29: 498-504, 1998.

15. Hu R, Wang FM, Yu L, Luo Y, Wu X, Li J, Zhang XM, Oehninger $S$ and Bocca $S$ : Antimüllerian hormone regulates stem cell factor expression in human granulosa cells. Fertil Steril 102: 1742-1750.e1, 2014.

16. Livak KJ and Schmittgen TD: Analysis of relative gene expression data using real-time quantitative PCR and the 2(-Delta Delta C(T)) method. Methods 25: 402-408, 2001.

17. Magee JA, Piskounova E and Morrison SJ: Cancer stem cells: Impact, heterogeneity, and uncertainty. Cancer Cell 21: 283-296, 2012.

18. Foster R, Buckanovich RJ and Rueda BR: Ovarian cancer stem cells: Working towards the root of stemness. Cancer Lett 338: 147-157, 2013. 
19. Anttonen M, Färkkilä A, Tauriala H, Kauppinen M Maclaughlin DT, Unkila-Kallio L, Bützow R and Heikinheimo M: Anti-Müllerian hormone inhibits growth of AMH type II receptor-positive human ovarian granulosa cell tumor cells by activating apoptosis. Lab Invest 91: 1605-1614, 2011.

20. Ha TU, Segev DL, Barbie D, Masiakos PT, Tran TT, Dombkowski D, Glander M, Clarke TR, Lorenzo HK, Donahoe PK and Maheswaran S: Müllerian inhibiting substance inhibits ovarian cell growth through an $\mathrm{Rb}$-independent mechanism. J Biol Chem 275: 37101-37109, 2000.

21. Nilsson E, Rogers N and Skinner MK: Actions of anti-Müllerian hormone on the ovarian transcriptome to inhibit primordial to primary follicle transition. Reproduction 134: 209-221, 2007.

22. Zhang W, Stoica G, Tasca SI, Kelly KA and Meininger CJ: Modulation of tumor angiogenesis by stem cell factor. Cancer Res 60: 6757-6762, 2000.

23. Huang B, Lei Z, Zhang GM, Li D, Song C, Li B, Liu Y, Yuan Y, Unkeless J, Xiong $\mathrm{H}$ and Feng ZH: SCF-mediated mast cell infiltration and activation exacerbate the inflammation and immunosuppression in tumor microenvironment. Blood 112: 1269-1279, 2008.

24. Liu J, Zhang Y, Zhao J, Yang Z, Li D, Katirai F and Huang B: Mast cell: Insight into remodeling a tumor microenvironment. Cancer Metastasis Rev 30: 177-184, 2011.

25. Shaw TJ and Vanderhyden BC: AKT mediates the pro-survival effects of KIT in ovarian cancer cells and is a determinant of sensitivity to imatinib mesylate. Gynecol Oncol 105: 122-131, 2007.
26. Jung YS, Kim HJ, Seo SK, Choi YS, Nam EJ, Kim S, Kim SW, Han HD, Kim JW and Kim YT: Anti-proliferative and apoptotic activities of Müllerian inhibiting substance combined with calcitriol in ovarian cancer cell lines. Yonsei Med J 57: 33-40, 2016.

27. Katiyar S, Jiao X, Wagner E, Lisanti MP and Pestell RG: Somatic excision demonstrates that c-Jun induces cellular migration and invasion through induction of stem cell factor. Mol Cell Biol 27: 1356-1369, 2007.

28. Barbie TU, Barbie DA, MacLaughlin DT, Maheswaran S and Donahoe PK: Mullerian Inhibiting Substance inhibits cervical cancer cell growth via a pathway involving p130 and p107. Proc Natl Acad Sci USA 100: 15601-15606, 2003.

29. Kano M, Sosulski AE, Zhang L, Saatcioglu HD, Wang D, Nagykery N, Sabatini ME, Gao G, Donahoe PK and Pépin D: $\mathrm{AMH} / \mathrm{MIS}$ as a contraceptive that protects the ovarian reserve during chemotherapy. Proc Natl Acad Sci USA 114: E1688-E1697, 2017.

30. Park SH, Chung YJ, Song JY, Kim SI, Pépin D, MacLaughlin DT, Donahoe PK and Kim JH: Müllerian inhibiting substance inhibits an ovarian cancer cell line via $\beta$-catenin interacting protein deregulation of the Wnt signal pathway. Int J Oncol 50: 1022-1028, 2017.

31. Chang HL, Pieretti-Vanmarcke R, Nicolaou F, Li X, Wei X, MacLaughlin DT and Donahoe PK: Mullerian inhibiting substance inhibits invasion and migration of epithelial cancer cell lines. Gynecol Oncol 120: 128-134, 2011. 